\title{
58. Using READ INTO and WRITE FROM
}

Instead of using MOVE to copy a record from the Working-Storage Division into the File Section before writing it to disk - this can all be done with one command - e.g.

\section{WRITE PRINT-LINE FROM HEADING-LINE}

AFTER ADVANCING 1 LINE.

(This assumes that PRINT-LINE is defined as a record in the FILE SECTION and that HEADING-LINE is the same length and is defined in the WORKINGSTORAGE SECTION).

This can also be used for data-files on disk - not just Printer-files - e.g.

WRITE STUDENT-RECORD FROM FIRST-YEAR-STUDENT-DETAILS.

In a similar way if a record needs to be moved into an area of the WorkingStorage Section after being read - then the command READ ... INTO may be used

- which has the same effect as a READ followed by a MOVE - e.g.

READ STUDENT-FILE INTO FIRST-YEAR-STUDENT-DETAILS AT END MOVE 'E' TO END-OF-FILE-INDICATOR

END-READ.

Exercise

Write a program which will display the following text on a page:

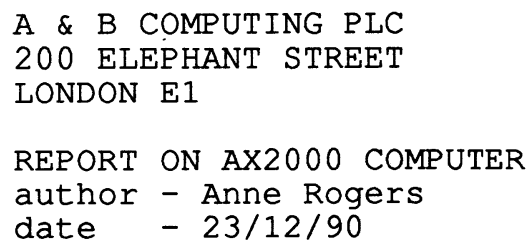

Make use of WRITE FROM. 